\title{
POSSIBILIDADES DE USO DIDÁTICO-PEDAGÓGICO EM ESPAÇO DIGITAL VIRTUAL 3D DO UNILASALLE NO METAVERSO SECOND LIFE
}

\author{
Cristina Martins, Centro Universitário La Salle/UNILASALLE \\ Ana Margô Mantovani, Centro Universitário La Salle/UNILASALLE \\ \{cristina.martins, margo\}@unilasalle.edu.br
}

Resumo: Este artigo apresenta o desenvolvimento de aplicações educacionais no Espaço Digital Virtual 3 Dimensões (EDV3D) do UNILASALLE, no metaverso Second Life $(S L)$. Com o objetivo de verificar como estas aplicações podem auxiliar os alunos em formação inicial no uso das diversas TDVs e, em especial, do metaverso $S L$, implementou-se o espaço temático Ateliê Digital Virtual. Os dados analisados são oriundos dos registros interativos no próprio ambiente e de questionários. Constatou-se que as aplicações desenvolvidas no EDV3D do UNILASALLE motivam e facilitam a aprendizagem dos alunos no que tange ao uso dessas tecnologias, uma vez que apresentam materiais diversificados, tais como: áudios, vídeos, machinimas, objetos interativos e animações, servindo de apoio para educação presencial e a distância.

Palavras-chave: Possibilidades didático-pedagógicas, Mundos digitais virtuais 3D, Second Life, Educação a distância.

\section{POSSIBILITIES OF USE DIDACTIC PEDAGOGICAL IN DIGITAL VIRTUAL 3D SPACE OF UNILASALLE IN THE METAVERSE SECOND LIFE}

Abstract: This article presents the development of educational applications in the Digital Virtual 3 Dimensions Space (DV3DS) of UNILASALLE, in the metaverse Second Life (SL). With the objective to check how these applications can help the students on the initial formation in the use of several TDVs and, in especial, of the metaverse SL, it was implemented the thematic space Ateliê Digital Virtual. The data analyzed from interactive registers in the own environment and questionnaires. It was found that the applications developed in the DV3DS of UNILASALLE motivate and facilitate the learning of the students with respect of the use of theses technologies, once that presents diversified materials, like: audios, videos, machinimas, interactive objects and animations, serving like support for the presence and distance education.

Keywords: Didactic pedagogical possibilities; Digital Virtual 3D Worlds, Second Life, Distance education.

\section{Introdução}

Desde seu surgimento, o computador agregado às Tecnologias Digitais Virtuais (TDVs) trouxe mudanças para as mais diversas áreas de conhecimento, inclusive para a Educação. Em paralelo a essas mudanças, surge uma nova geração de alunos, também definida por geração digital ou, conforme Veen e Vrakking (2009), geração Homo zappiens. Para estes autores, a tecnologia moldou o modo de ser do Homo zappiens, pois esta geração pensa em redes e colaborativamente, por isso suas estratégias de aprendizagem mudaram, são desafiadoras, permitindo aos educadores a oportunidade de ensinar de maneira inovadora.

Em paralelo com esta geração digital percebe-se o crescimento da Educação a Distância (EaD), que traz novos conceitos em relação ao tempo e espaço, minimizando 
a distância geográfica e ampliando as possibilidades de interação, uma vez que se utiliza das diversas TDVs e, em especial dos metaversos - Mundos Digitais Virtuais em 3 Dimensões (MDV3D).

De acordo com Schlemmer e Backes (2008, p.522) o metaverso é “[...] uma tecnologia que se constitui no ciberespaço e se "materializa" por meio da criação de Mundos Digitais Virtuais em 3D - MDV3D, no qual diferentes espaços para o viver e conviver são representados em 3D. Destacam-se ainda como características dos metaversos, as possibilidades de utilizar diversas linguagens de comunicação: textual, oral, gestual e gráfica, que abrem novas possiblidades para alcançar-se um alto grau de interação. Ainda, as autoras referidas apontam que "as pesquisas na área de mundos digitais virtuais são relativamente recentes se comparadas a outras tecnologias" (2008, p.524), daí a importância da realização de estudos nessa área, em especial, na utilização dos metaversos-MDV3D no campo educacional.

Considerando as características dos metaversos-MDV3D, que possibilitam inúmeras formas de aplicações educacionais, conteúdos interativos através de animações, simulações e programação de eventos e scripts, e tendo em vista que a instituição destas autoras possui um Espaço Digital Virtual em 3 Dimensões (EDV3D) no metaverso Second Life (SL), ainda pouco explorado, surgiu a necessidade de ampliar as possibilidades didático-pedagógicas de uso deste espaço. Para tal, implementou-se um espaço temático denominado Ateliê Digital Virtual contendo as seguintes aplicações: Central de Teleporte, Tecnoteca, Explorando o Second Life e Espaço de Interações.

Assim sendo, questiona-se: como estas aplicações educacionais poderão auxiliar os alunos em formação inicial no uso das diversas TDVs e, em especial, do metaverso $S L$ ?

Para dar conta de tal problematização, este estudo insere-se em uma abordagem epistemológica construtivista/sócio-interacionista com ênfase no processo de construção do conhecimento, através das interações dos alunos entre seus pares e no metaversoMDV3D SL.

\section{Tecnologias Digitais Virtuais e Educação a Distância}

A inserção e utilização adequada das TDVs no contexto educacional tem provocado o surgimento de novas concepções de ensino e aprendizagem. O uso dessas tecnologias na educação proporciona um ambiente facilitador e instigante, onde a reflexão crítica, a busca por conhecimento e a aprendizagem sucessiva e independente afloram.

A integração dessas tecnologias aos conteúdos, habilidades e competências trabalhados no currículo escolar tende a tornar a aprendizagem mais efetiva e significativa, principalmente se pensarmos em atender a demanda da geração Homo zappiens que instiga os educadores a repensar as suas atuais práticas pedagógicas.

Dentre as novas possibilidades de construção de conhecimento e modalidades de ensino proporcionadas pela Sociedade em Rede (CASTELLS, 2007), a Educação a Distância $(\mathrm{EaD})$ tem se tornado uma forte tendência na educação, mostrando-se fundamental "[...] para atender a situações muito diferenciadas de uma sociedade cada vez mais complexa."(MORAN, 2009, p. 56). Conforme Mattar e Valente (2007), a EaD pode possibilitar a manipulação do espaço e do tempo em favor da educação. Também se entende que o professor "[...] desde o princípio mesmo de sua experiência formadora, [...] se convença definitivamente de que ensinar não é transferir conhecimento, mas criar as possibilidades para a sua produção ou a sua construção.” (FREIRE, 2009, p.22). 
No entanto, percebe-se que muitos professores reproduzem na $\mathrm{EaD}$ uma concepção tradicional de ensino, pautada ainda no paradigma instrucional. Não é esse profissional que se espera em $\mathrm{EaD}$, até porque, os alunos da geração digital, não são "folhas de papel em branco", mas sim "hipertextos"(textos não-lineares) repletos de informações que precisam ser selecionadas, contextualizadas, para que se transformem em conhecimento.

Também se percebe que muitos ambientes virtuais de aprendizagem (AVAs) são engessados, sem flexibilização de recursos, reforçando o distanciamento entre alunos e professores, afetando assim as interações e mediações necessárias para a efetivação de qualidade dos processos de ensinar e de aprender. Neste contexto, verifica-se uma nova tendência em EaD que surge para minimizar as dificuldades encontradas no uso dessa modalidade, especialmente no que se refere aos processos de interação. Estamos nos referindo ao uso de metaversos-MDV3D.

\section{Metaversos, MDV3D e Second Life: nova tendência na EaD}

Schlemmer e Backes (2008) destacam que os metaversos fazem referência " [...] a um ambiente de total imersão, que possibilita a construção de MDV3D pelos próprios sujeitos que o "habitam"." (p.522). Então, dentro de um metaverso pode-se representar a realidade digital e virtualmente, sendo possível construir representações do mundo "real", agindo e interagindo através da telepresença por meio de um avatar (representação da identidade digital virtual).

Além disso, os metaversos são considerados híbridos, por agregarem diferentes características de várias ferramentas, tais como jogos, ambientes virtuais, chats, comunidades virtuais, entre outros, proporcionando a construção de aplicações educacionais. Dessa forma, as possibilidades de mediação pedagógica através da telepresença podem proporcionar maior envolvimento com o que está sendo desenvolvido devido às possibilidades de imersão através do avatar, tornando o ambiente mais interativo, no sentido de que é possível comunicar-se de diferentes formas e simultaneamente por estar imerso no mesmo espaço e tempo, aumentando e potencializando a comunicação, interação e troca de experiências. Esse tipo de interação não é possível alcançar através de alguns AVAs, que se mostram menos flexíveis, e proporcionam menos interatividade e simultaneidade nas ações.

Dentre os diversos metaversos destacamos o Second Life $(S L)$ que é o mais popular até este momento. Além das características já referidas, também apresenta ferramentas avançadas que possibilitam a modelagem e programação de objetos através da linguagem Linden Scripting Language (LSL).

Mattar e Valente ressaltam que o $S L$ "[...] é uma excelente plataforma para promover uma educação on-line e flexível [...] Os professores podem compartilhar informações com seus alunos de diversas maneiras, como: textos, slides, áudio, vídeos, em ambientes que simulam a realidade" (2007, p.180).

Diversas universidades já se aventuraram no uso do $S L$ no contexto educacional, tais como: no cenário internacional: Estados Unidos - Harvard, Standford; na Inglaterra - Open University; em Portugal - Universidade de Aveiro e do Porto; no cenário nacional: Senac-SP, Universidade Presbiteriana Mackenzie, Universidade Anhembi Morumbi; no cenário regional: Universidade Federal do Rio Grande do Sul (UFRGS), Pontifícia Universidade Católica do Rio Grande do Sul (PUCRS), Centro Universitário La Salle/Canoas (UNILASALLE), Universidade do Vale dos Sinos (UNISINOS), entre outras. 
Considerando as características destacadas, pode-se inferir que os metaversos MDV3D tornam-se plataformas para a $\mathrm{EaD}$, minimizando dificuldades encontradas no uso de alguns AVAs atualmente utilizados. Também, entende-se que o metaverso $S L$, configura-se como um software apropriado para o desenvolvimento de aplicações educacionais de qualidade, que podem ser utilizadas tanto em $\mathrm{EaD}$, quanto servir de apoio à educação presencial.

\section{Aplicações educacionais no Espaço Digital Virtual 3D do UNILASALLE no metaverso Second Life}

Para a construção das aplicações educacionais no EDV3D do UNILASALLE, realizou-se primeiro um planejamento técnico-didático-pedagógico em consonância com a finalidade educacional do MDV3D, considerando a perspectiva construtivista/sócio-interacionista, buscando interação, trabalho em rede, colaboração, cooperação e autonomia por parte dos alunos. Assim, os espaços temáticos e os tipos de aplicações educacionais implementadas em cada espaço priorizaram estas características.

Além do metaverso $S L$, que permite a modelagem e programação dos objetos, com o propósito de apresentar materiais diversificados, tais como: áudios, vídeos, machinimas (vídeos filmados em mundos virtuais) e animações, utilizou-se ainda os software: - Adobe Photoshop CS4 para edição de imagens; - Camtasia Studio 7 para edição e produção de vídeo-aulas e machinimas; - Microsoft Office Power Point para produção de slides; - iSpring Free para conversão dos slides produzidos com Microsoft Office Power Point na extensão Flash.

Estes softwares auxiliaram na integração de recursos e mídias para a construção das aplicações educacionais no metaverso $S L$, permitindo assim maior interação e diversidade de mídias. Estas aplicações foram implementadas em um espaço temático denominado Ateliê Digital Virtual.

\subsection{Ateliê Digital Virtual}

O Ateliê Digital Virtual contempla o $4^{\circ}$ andar do EDV3D do UNILASALLE e contém as seguintes aplicações: Central de Teleporte ${ }^{1}$, Tecnoteca, Explorando o Second Life e Espaço de Interações, conforme Figura 1. Aqui também se encontram vários painéis referentes às TDVs que mostram os projetos de aprendizagem multimídia desenvolvidos em diversas disciplinas ministradas pela professora co-autora deste artigo.

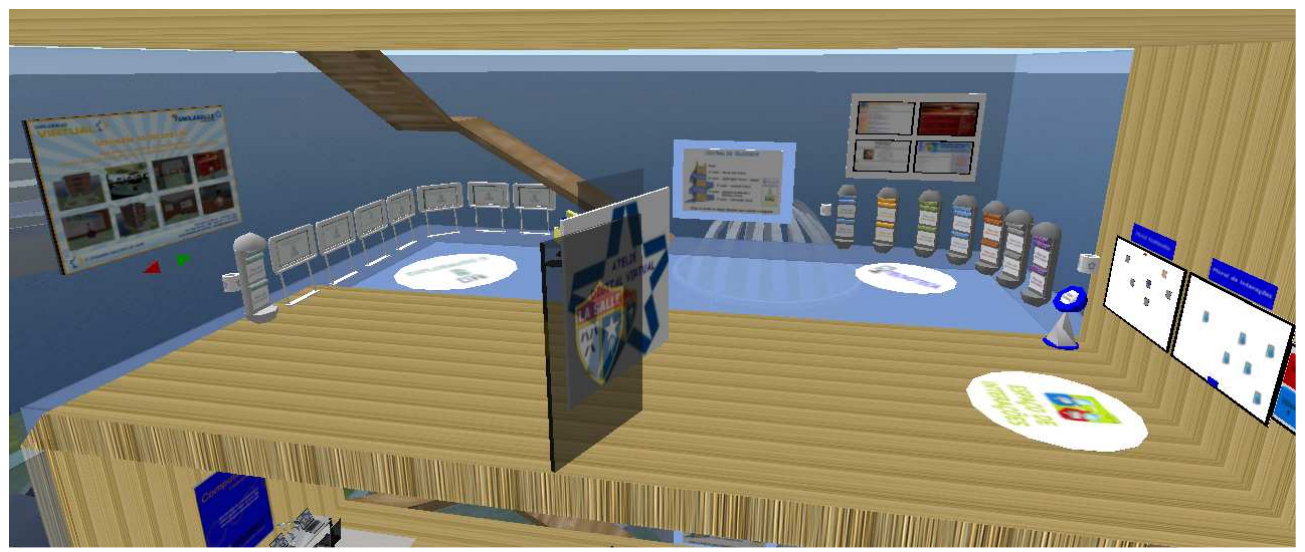

Figura 1 - Ateliê Digital Virtual

Fonte: Autoria própria, 2010. 
$\mathrm{Na}$ Central de Teleporte do EDV3D do UNILASALLE, localiza-se o Espaço Inicial do Ateliê Digital Virtual e um Mural Integrador com a descrição destes espaços.

No espaço da Tecnoteca foram produzidos slides sobre diversas TDVs, tais como blogs, wikis, podcasts, webquests, entre outras, apresentando as potencialidades educacionais destas tecnologias e sugestões de leituras acadêmicas. Além disso, também foram produzidas vídeo-aulas sobre as formas de utilização das tecnologias referidas. Para construir estas aplicações, utilizou-se como metáfora cápsulas do tempo, representando uma visão futurista em relação ao uso das TDVs, conforme se mostra na Figura 2. Estas cápsulas apresentam texturas de mídia, que permitem ao avatar acessar e interagir com os slides e as vídeo-aulas das TDVs apresentadas.

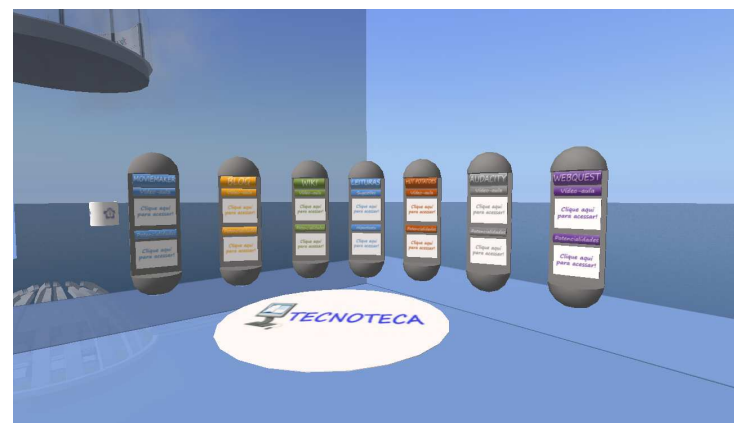

Figura 2 - Tecnoteca

Fonte: Autoria própria, 2010.

No espaço Explorando o Second Life, foram produzidos vídeo-aulas, machinimas e um glossário apresentando conteúdos considerados relevantes para auxiliar os iniciantes no uso do $S L$, apresentadas também em forma de cápsulas com displays, que podem ser acessadas pelos avatares. Neste espaço ainda encontra-se os objetos de interação: o baú dos avatares que oferece roupas ao avatar para sua customização e centrais de teleporte, que oferecem landmarks (indicações de locais para o avatar se teletransportar) para ilhas de Freebies (ilhas com objetos que podem ser adquiridos gratuitamente) e Sandbox (area pública onde os avatars podem construir objetos), conforme mostra a Figura 3.

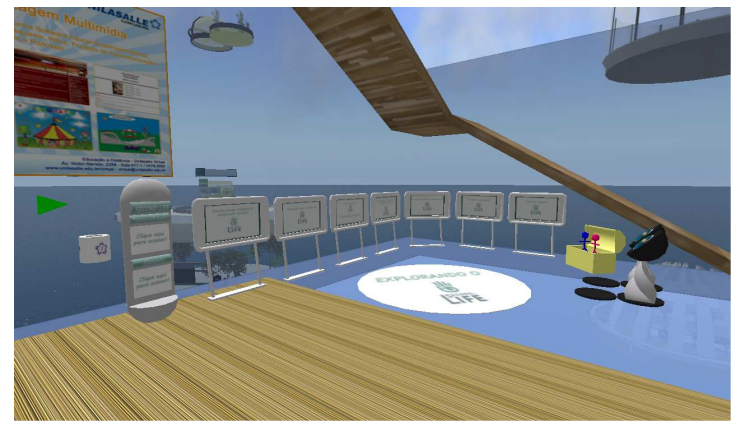

Figura 3 - Explorando o Second Life

Fonte: Autoria própria, 2010.

O Espaço de Interações possibilita aos avatares interagirem com objetos através das seguintes aplicações educacionais (Figura 4):

- Painel dos Desafios: disponibiliza notecards (anotações, suporte para texto) com a descrição dos desafios a serem realizados;

- Mural de Interações: permite a postagem e compartilhamento de notecards;

- Mural Multimídia: permite postar e compartilhar fotos, áudios e anotações. 


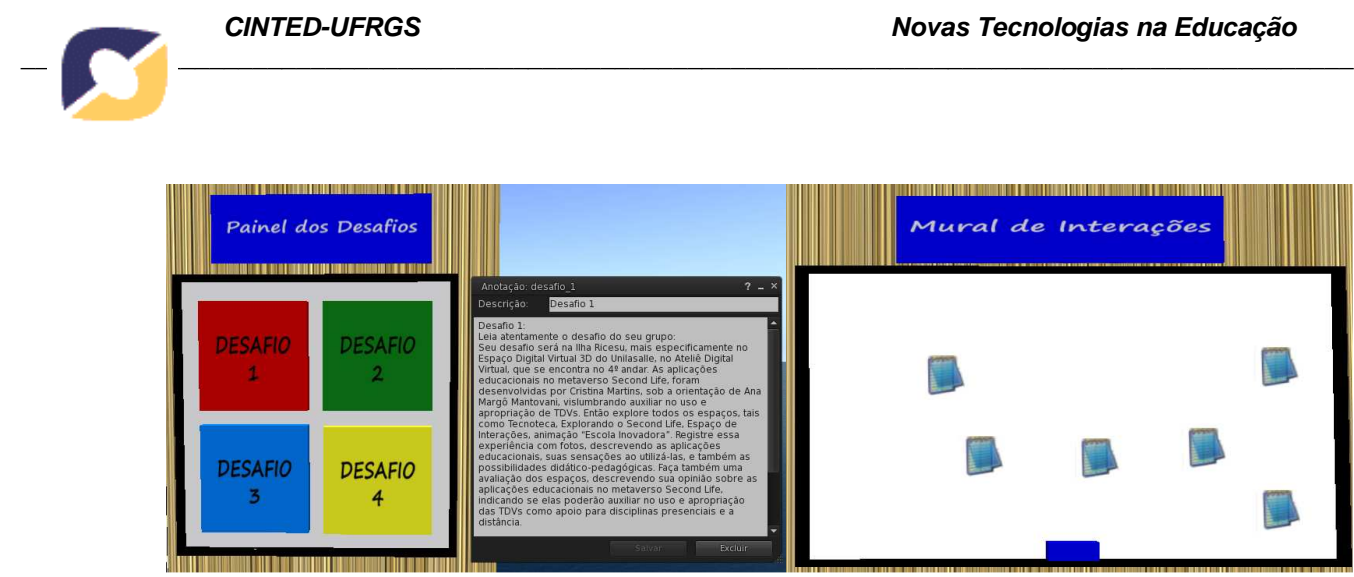

Figura 4 - Painel dos Desafios e Mural de Interações.

Fonte: Autoria própria, 2010.

- Animação Escola Inovadora: Esta animação propõe uma reflexão sobre uma escola inovadora na "Sociedade de Redes", conforme se mostra na Figura 5. O avatar, ao clicar na cápsula contendo o teleporte, é direcionado para uma esfera que se encontra em outro local (ao alto do EDV3D do UNILASALLE). Esta animação contém várias telas com a representação de diversas TDVs que podem ser acessadas através de links, e uma placa que inicia a animação. Conforme o avatar interage, surgem legos apresentando conceitos, em forma de notecards, condizentes com a proposta de uma Escola Inovadora. Ao final da animação, propõe-se uma reflexão a respeito, que deve ser postada através de um notecard no Baú do Desafio.

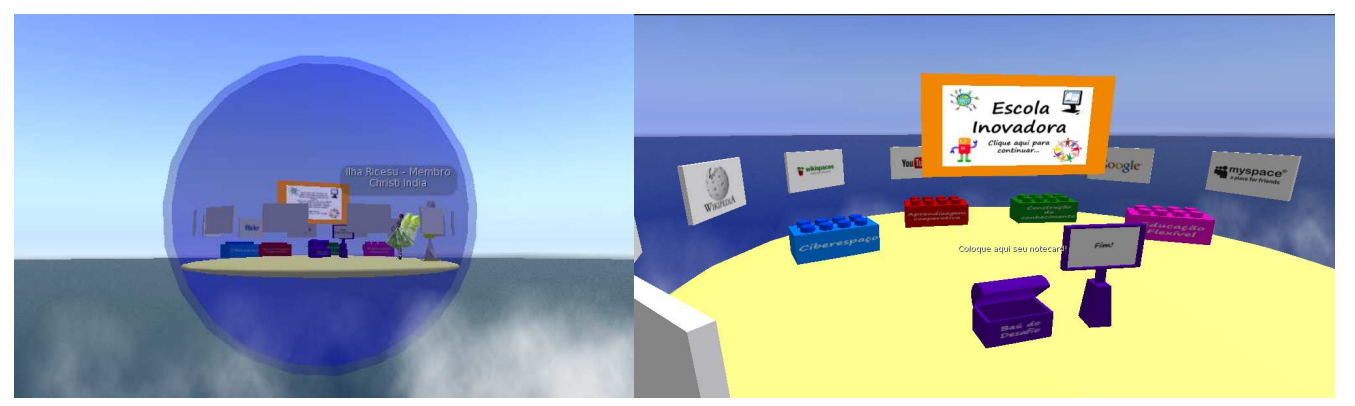

Figura 5 - Animação "Escola Inovadora"

Fonte: Autoria própria, 2010.

\section{Avaliação das aplicações educacionais desenvolvidas no EDV3D do UNILASALLE}

As aplicações educacionais no metaverso $S L$ foram avaliadas de forma qualitativa na modalidade b-learning ${ }^{2}$ sendo que o campo empírico constituiu-se de alunos provenientes dos cursos de Computação- Licenciatura e de colaboradores de um grupo de pesquisa de área afim. Foram utilizados como instrumentos de pesquisa: questionários, observação da interação desses alunos com as aplicações educacionais implementadas no Ateliê Digital Virtual e desafios (em forma de notecard) apresentados no próprio ambiente no Espaço de Interação.

Os extratos de análise apontam que as aplicações educacionais desenvolvidas no EDV3D do UNILASALLE motivam os alunos na utilização das diversas TDVs e na exploração do metaverso $S L$, por apresentarem recursos facilitadores deste aprendizado, uma vez que apresentam materiais diversificados, tais como: áudios, vídeos, machinimas e animações.

Em relação à observação da interação desses alunos com as aplicações educacionais implementadas (encontro presencial) no Ateliê Digital Virtual constatouse que: 
- utilizaram a linguagem textual, gestual e gráfica do metaverso $S L$ para comunicação e interação, com exceção do áudio, uma vez que estavam presentes no espaço físico presencial;

- demonstraram facilidade em utilizar a maior parte das aplicações educacionais desenvolvidas;

- as aplicações educacionais proporcionaram maior imersão no ambiente, pois se sentiram encorajados a realizar os desafios apresentados, interagindo através dos notecards postados no Mural Multimídia e no Mural de Interações, conforme se mostra na Figura 6:

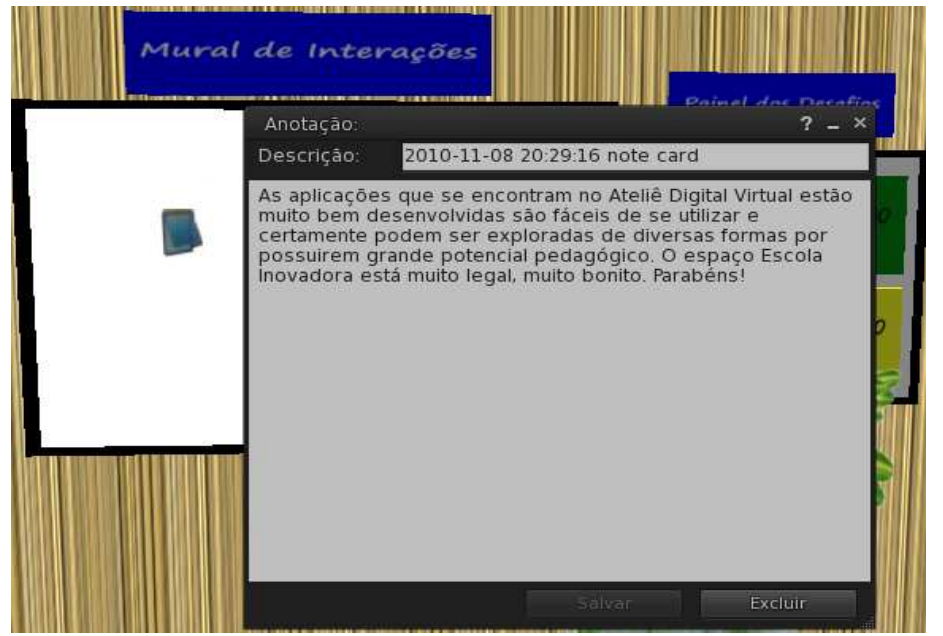

Figura 6 - Notecard Desafio: aluno 1 - Computação-Licenciatura

Fonte: Autoria própria, 2010.

Em relação à análise dos questionários e a resolução dos desafios realizados na modalidade a distância, destaca-se os seguintes indicadores de análise:

1- Uso de metaversos, MDV3D e $S L$ :

A maioria já possuía alguma experiência, pois já haviam utilizado o $S L$, tanto como apoio à educação presencial, quanto a distância, porém alguns alunos não haviam percebido as possibilidades pedagógicas que os metaversos apresentam, conforme o seguinte extrato de análise:

"Quando utilizei o Second Life achei interessante os gráficos e cenários construídos, a riqueza de detalhes nas construções, a movimentação dos avatares. Mas a princípio não enxergava possibilidades pedagógicas no Second Life, após conhecer melhor reconheci essas possibilidades" (aluno 2 - Computação-Licenciatura)

Dessa forma, concorda-se com Mattar (2008, p.3) quando afirma que, ao utilizar o $S L$, os alunos "deixam de ser consumidores passivos do aprendizado [...] para serem envolvidos na criação de suas próprias atividades, suas experiências e dos seus próprios ambientes de aprendizagem".

\section{2- Ateliê Digital Virtual - Espaço Tecnoteca:}

Verificou-se que as aplicações desenvolvidas neste espaço auxiliam na utilização das diversas TDVs abordadas, conforme relato:

\footnotetext{
"Os materiais orientam passo a passo os meios de sua utilização, bem como sinalizam o seu potencial pedagógico, isto é, perfeita integração em relação as questões mais técnicas com a pedagógica" (sujeito 1 - colaborador de um Grupo de Pesquisa)
} 
Além disso, os alunos também sinalizam que as aplicações educacionais implementadas podem servir de apoio para disciplinas presenciais e a distância, conforme notercard postado no Mural de Interações:

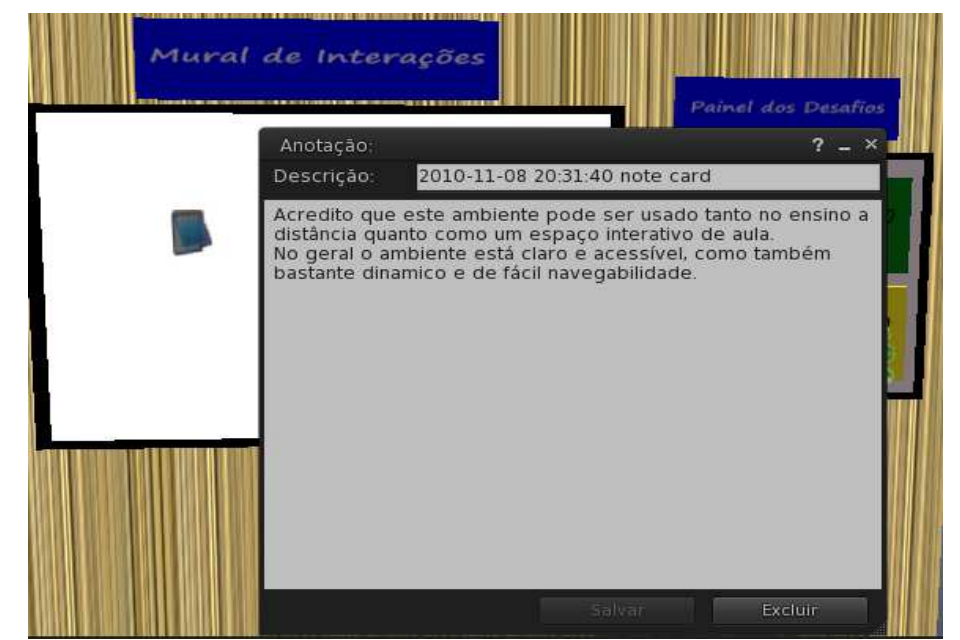

Figura 8 - Notecard Desafio: aluno 2 Computação-Licenciatura

Fonte: Autoria própria, 2010.

\section{3- Ateliê Digital Virtual - Espaço Explorando o Second Life:}

Percebeu-se que as aplicações desse espaço auxiliaram os alunos que nunca haviam utilizado o $S L$ a interagir com o metaverso $S L$, conforme se evidencia nos seguintes depoimentos:

"As aplicações desse espaço dão uma idéia inicial para o usuário sobre algumas questões do Second Life." (aluno 3 - Computação-Licenciatura)

"As aplicações desse espaço estimulam o usuário a iniciar a exploração do SL" (aluno 1 Computação-Licenciatura)

4- Ateliê Digital Virtual - Espaço de Interações:

Este é o espaço que proporciona maior interação entre o aluno (representado pelo seu avatar) com o próprio metaverso, permitindo também um espaço de mediação com o professor, pois instiga o aluno a realizar atividades através de desafios e postagem de materiais em diversos formatos. Evidenciou-se, a partir dos extratos de análise a seguir, que este espaço é importante para o aluno perceber o potencial do metaverso $S L$ em relação à interação com objetos, atividades diversificadas e registro das atividades solicitadas pelo professor, bem como o registro de sua vivência ao longo das interações no MDV3D.

"Esse espaço possibilitou interagir mais com os objetos que ali estavam. Além de poder fazer a postagem das minhas colaborações, foi possível ler as colaborações dos colegas que já haviam interagido." (aluno 1 - Computação-Licenciatura)

"Através deste espaço podemos compartilhar o conhecimento que experienciamos interagindo com os objetos dispostos nele. Também senti a presença do professor como se estivesse em uma sala de aula real, achei este espaço mais interativo e percebi as potencialidades educacionais que existem no metaverso." (aluno 2 - Computação-Licenciatura)

"Certamente, a exploração das aplicações nos faz ter idéias novas para desenvolvimento de atividades educacionais." (sujeito 1 - colaborador de um Grupo de Pesquisa) 
Assim sendo, concorda-se com Lévy, quando afima que "[...]Ao interagir com o mundo virtual, os usuários o exploram e o atualizam simultaneamente. Quando as interações podem enriquecer ou modificar o modelo [digital], o mundo virtual torna-se um vetor de inteligência e criação coletiva" (2008, p.75)

Constatou-se, devido à complexidade exigida para a postagem de materiais nos murais, por conta de algumas limitações existentes nas ferramentas de modelagem e programação de objetos do $S L$, algumas dificuldades na utilização destes murais:

"Precisei de auxilio para conseguir postar os materiais, fotos e textos." (aluno 3 - ComputaçãoLicenciatura)

Assim sendo, para minimizar estas dificuldades, implementou-se em todos os espaços do Ateliê Digital Virtual, objetos de ajuda, oferecendo notecards aos avatares com esclarecimentos (tutoriais) referentes à postagem dos materiais nos murais.

5- Referente à animação "Escola Inovadora":

Observou-se que a reflexão proposta foi realizada de uma forma significativa, conforme mostra o seguinte extrato:

"O espaço escola inovadora ficou muito interessante e demonstrou ser outro local que proporciona interação entre sujeito e objeto. Os conceitos apresentados são importantes para o contexto da Informática na Educação e para a EaD, e principalmente devem ser discutidos em formação de professores. Além disso, este espaço apresenta links para tecnologias que podem ser utilizadas na educação, isto é, ótimas indicações de ensino e de aprendizagem para a prática pedagógica do professor." (sujeito 1 - colaborador de um Grupo de Pesquisa)

Através de uma avaliação geral referente às aplicações educacionais construídas no Ateliê Digital Virtual, constatou-se que estas aplicações podem auxiliar os alunos em formação inicial no uso das TDVs e de metaverso-MDV3D, instigando-os a utilizar estas tecnologias em suas práticas pedagógicas.

"Estas aplicações estão bem produzidas e de fácil entendimento. Quanto ao ambiente posso dizer que está bem acessível e de fácil locomoção dentre os espaços produzidos, desta forma, não tenho nenhuma crítica sobre o trabalho apenas o incentivo na descoberta de novos recursos a serem explorados." (aluno 1 - Computação-Licenciatura)

"Achei as aplicações muito interessantes, certamente houve todo um cuidado no desenvolvimento das aplicações, nas questões visuais e conceituais. A circulação pelo ambiente é muito fácil, a localização das aplicações também. A ajuda fornecida ao usuário para navegação é muito útil." (aluno 2 - Computação-Licenciatura)

Desse modo, corrobora-se com Mattar (2008) quando afirma que o metaverso $S L$ configura-se como um potente software para o desenvolvimento de aplicações educacionais, apresentando inúmeras possibilidades, tais como texturas de mídia, machinimas, objetos com interação, animações, entre outros. Além disso, também concorda-se com o autor quando ressalta que o metaverso $S L$ é uma ótima plataforma para promover a educação on-line e flexível, entendida aqui como uma nova tendência que incorpora as modalidades presencial e a distância.

\section{Considerações finais}

Dentre as novas tendências na $\mathrm{EaD}$, que emergem minimizando questões como AVAs sem flexibilização dos recursos e a falta da presença física do professor, destacam-se os metaversos - MDV3D, uma vez que apresentam características de várias ferramentas, tais como jogos, ambientes virtuais, chats, comunidades virtuais, entre 
outros, proporcionando maior interação e "sensação de presença". A possibilidade de construção de MDV3D e de aplicações educacionais que agregam valor nestes mundos virtuais sinaliza um novo caminho na produção do conhecimento.

Os extratos de análise apontam que as aplicações educacionais desenvolvidas no EDV3D do UNILASALLE, motivam os alunos na utilização das diversas TDVs e na exploração do metaverso $S L$, por apresentarem recursos facilitadores deste aprendizado, uma vez que apresentam materiais diversificados, tais como: áudios, vídeos, machinimas e animações. Constatou-se que tais aplicações educacionais, que podem ser utilizadas por quem tiver interesse no uso das diversas TDVs e metaversos no contexto educacional, contribuem para o desenvolvimento de processos formativos servindo de apoio para a educação presencial e a distância.

\section{Notas do texto}

${ }^{1} \mathrm{O}$ termo teleporte faz referência a teleportar, que significa transporte instantâneo, permite o avatar se deslocar de uma região a outra no $S L$.

${ }^{2}$ Destaca-se que na modalidade b-learning ou blended learning ocorrem encontros presencias e a distância através de interações síncronas e assíncronas.

\section{Referências}

CASTELLS, Manuel. A Sociedade em Rede. 10ª ed. São Paulo: Paz e Terra, 2007. 698 p.

FREIRE, Paulo. Pedagogia da Autonomia: saberes necessários à prática educativa. 39 ed. São Paulo: Paz e Terra, 2009. 148 p.

LÉVY, Pierre. Cibercultura. 2 ed. São Paulo: Editora 34, 2008. 260 p.

MATTAR, João. $O$ uso do Second Life como ambiente virtual de aprendizagem. In: IV SEMINÁRIO JOGOS ELETRÔNICOS, EDUCAÇÃO E COMUNICAÇÃO CONSTRUINDO NOVAS TRILHAS. Salvador, 2008.

MATTAR, João; VALENTE, Carlos. Second Life e Web 2.0 na educação: o potencial revolucionário das novas tecnologias. São Paulo: Novatec, 2007. 279 p.

MORAN, José Manuel. Modelos e avaliações do ensino superior a distância no Brasil. Educação Temática Digital, Campinas, v.10, n.2, p. 54-70, jun. 2009.

SCHLEMMER, Eliane; BACKES, Luciana. Metaverso: Novos espaços para a construção do conhecimento. In: Revista Diálogo Educacional: Programa de Pós Graduação em Educação da PUCPR. Curitiba, n.24, p.519-532,maio/ago 2008.

VEEN, Wim; VRAKKING, Ben. Homo Zappiens: educando na era digital, Porto Alegre: Artmed, 2009. 139 p. 